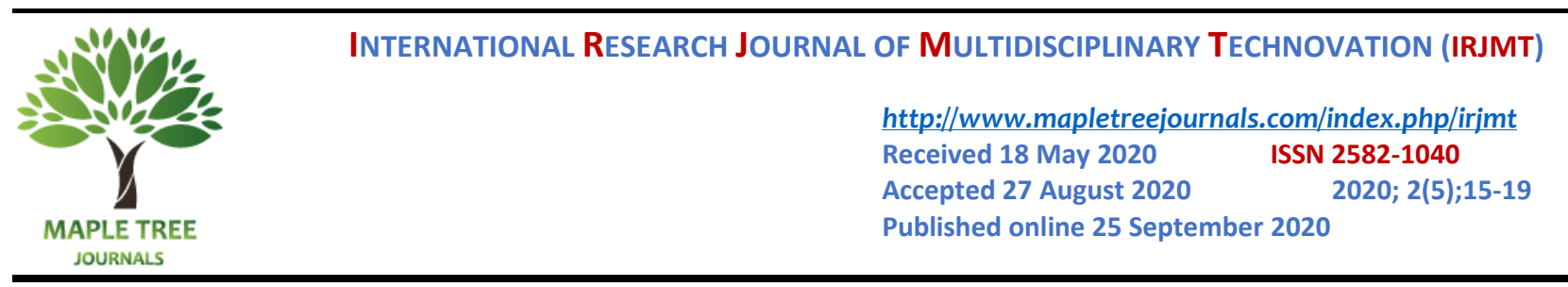

\title{
Orphanage Helping System
}

\author{
K. Santhosh Kumar ${ }^{1}$, P. Ashish Kumar ${ }^{1}$, V.K.G. Kalaiselvi ${ }^{1}$ \\ ${ }^{1}$ Department of Information Technology, Sri Sairam Engineering College, West Tambaram, Chennai-44, Tamil \\ Nadu, India. \\ *Corresponding author E-Mail ID: Santhoshkumar25051999@gmail.com
}

DOI: https://doi.org/10.34256/irjmt2053

\begin{abstract}
An orphanage is a residential institution devoted to the care of orphan-children whose parents are unwilling or unable to take care of them. The problem of orphan is acute due to urbanization and industrialization. Need for each of the orphanages varies in different categories such as food, money, clothes, medicine. Most of the people would like to help the orphanages but the major problem is that they have any idea on how to approach these orphanages. The main objective of this application is to develop a centralized site for orphanages. In our proposed system we try to create an interface between Orphanages\Old age Homes which are in need of charity and people/Volunteers who are willing to help these people. Volunteers can also approach the Orphanage managers regarding the help that they can afford. People can donate through Internet Banking or Online Money Payment applications.
\end{abstract}

Keywords: Orphanage, Volunteers, Centralized site, Charity.

\section{Introduction}

This idea comes under the 2nd Sustainable Development Goals (SDG) of "Zero hunger". Most of the children in orphanages suffer from malnutrition because they are fed with less amount or unhealthy food. Due to low caring and unwilling to take care of children by their parents the count of children in orphanages had increased linearly. Although the count of children is increasing, the charity provided for the orphanages is lesser in ratio. With the help of our OHS site this problem can be easily resolved or reduced [1]. This OHS is developed in order to increase or ease the charity provided for the orphanages [2]. Site Builder software can be used to develop the site with ease. This software provides hundreds of readymade templates and offers great customization options to design your layouts for the site from scratch level.

\section{Existing System}

Existing Systems consists of only the orphanages details such as, address, contact numbers etc., it does not have any centralized or separate website for orphanages.

\section{Drawbacks in Existing System}

The main drawback in existing system is people can view only the address of the particular orphanages which are searched by the users. In that people cannot do any donation or sponsorships. And this is the main disadvantage of orphanages which are in need of getting help from others.

\section{Proposed System}

In our proposed system we try to create an interface between Orphanages and Old age Homes which are in need of charity and people/Donors who are willing to help these people. Most 
of the people would like to help the orphanages but the major problem is that they have no idea on how to approach these orphanages. Need for each orphanage varies in different categories such as food, money, clothes, medicine. Through our proposed system the donors can actually select the category in which they like to help.

\section{System Architecture}

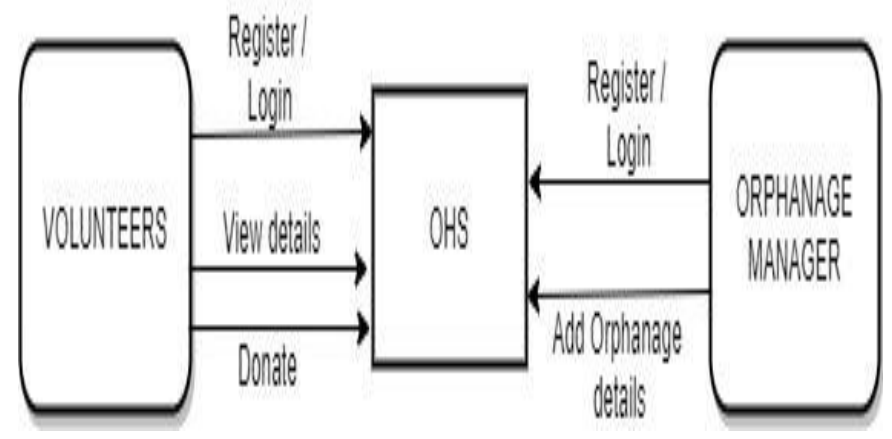

\section{Use Case Diagram}

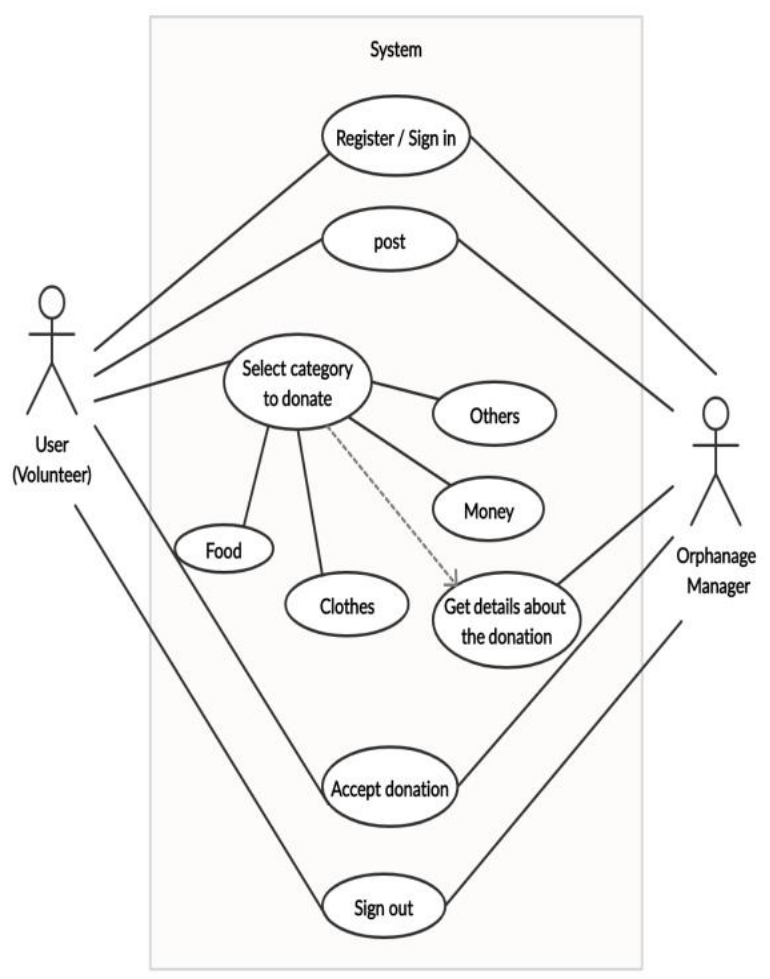

\section{Modules}

\section{a) Registration}

Users can visit the site by registering their details. The Registration can be performed in two different categories as User/Volunteer registration and Orphanage registration. The users can register to this site by providing their details like Name, Mobile number, email id etc. After that the registration process the users/volunteers can enter into the site by logging in with their user credentials. The Orphanage managers also registers their orphanage details providing with Orphanage name, Orphanage Govt Registration number, No. of children in the orphanage, contact number, Address etc. 


\section{b) Posting Needs}

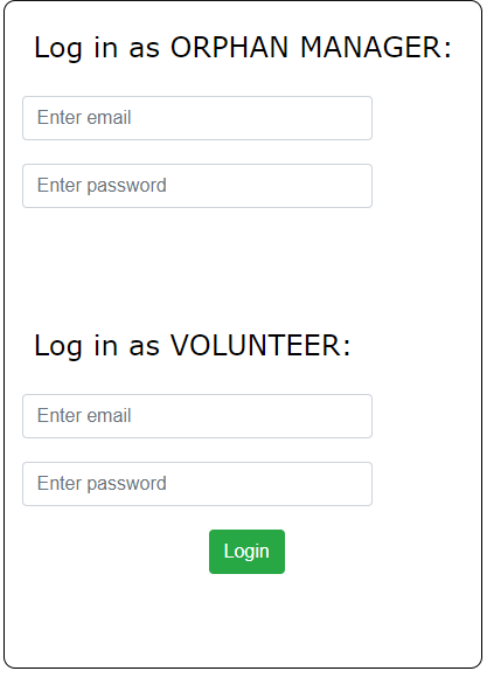

The Orphanage mangers post their orphanage details and the charity needed for the orphanage. Need for each orphanage varies in different categories such as food, money, clothes, medicine and other things. The manager specifies the most needed category required for the orphanage.

The Volunteers can also post the details on which category they are willing to donate. If the user wishes to do any help to the orphanage, they can approach the orphanage mangers through the information provided. And the Orphanage Manager can also approach the volunteers with the posted details.

\section{c) Fund Transfer}

The Volunteers can donate money to orphanages as their wish. The volunteers can get the account details of the Trust by contacting the orphanage manager. The money can be transferred through online money payment / Banking applications or Net-banking. The funds will be transferred to the Trust account of the orphanages. Some of the examples for online money payment applications are

- Google pay (Tez),

- Paytm,

- Internet banking.

\section{Select a payment method}

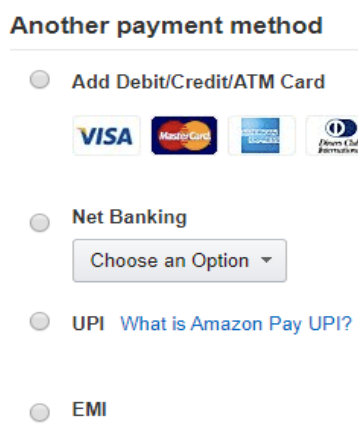




\section{d) Other Donations}

The other categories of donation like food, clothes, medicines, and other items can be provided to the Orphanages by contacting the orphanage manager and providing the donation things or the donation can be directly provided by the volunteers by visiting the orphanages.

Interested volunteers can also provide with scholarship facilities to the orphan children for completing a quality education.

\section{Future Enhancement:}

Some of the future enhancement ideas of OHS are

$>$ All Orphanages and Old age Homes across India can be included.

$>$ Education and medical details of the children can be added to the Orphanage details.

$>$ Notifications via SMS can be sent for donation and necessary needs required to orphanages.

\section{Conclusion}

A study by an International Children's Charity for orphaned and abandoned children has found that 4\% (20 million) of India's child population are orphans. Most of children in orphanages have been abandoned by their parents. In fact, the estimates state that only $0.3 \%$ of these orphans are children whose parents have actually died. Each of them can't be afforded by the orphanages, so people should come forward to make difference in their lives. Each penny counts.

\section{References:}

[1] A.P. Junfithrana, E. Liani, M. Z. Suwono, D. Meldiana, A. Suryana, (2018) Rice Donation System in Orphanage Based on Internet of Things, Raspberry-Pi, and Blockchain, In 2018 International Conference on Computing, Engineering, and Design (ICCED), IEEE, 235-238.

[2] M. Archana, K. Mouthami, Charity Connecting System, International Journal of Latest Technology in Engineering, Management \& Applied Science, 3 (2014) 137-141

\section{Acknowledgement Nil}

\section{Funding}

This study was not funded by any grant

\section{Conflict of interest}

None of the authors have any conflicts of interest to declare.

\section{About The License}

The text of this article is licensed under a Creative Commons Attribution 4.0 International License 


\section{Cite this Article}

K. Santhosh Kumar, P. Ashish Kumar, V.K.G. Kalaiselvi, Orphanage Helping System, International Research Journal of Multidisciplinary Technovation, Vol 2, Iss 5 (2020) 15-19. DOI: https://doi.org/10.34256/irimt2053 